\title{
Gene-Environmental Interactions as Metabolic Drivers of Nonalcoholic Steatohepatitis
}

\author{
Somaya Albhaisi ${ }^{1}$ and Arun J. Sanyal ${ }^{2 *}$ \\ ${ }^{1}$ Department of Internal Medicine, Virginia Commonwealth University, Richmond, VA, United States, ${ }^{2}$ Division of \\ Gastroenterology, Hepatology and Nutrition, Department of Internal Medicine, Virginia Commonwealth University, Richmond, \\ VA, United States
}

Nonalcoholic fatty liver disease (NAFLD) has emerged as a leading cause of chronic liver disease worldwide in the past few decades as a consequence of the global obesity epidemic and is associated with significant morbidity and mortality. NAFLD is closely associated with components of the metabolic syndrome, type 2 diabetes mellitus and cardiovascular disease, suggesting a plausible metabolic mechanistic basis. Metabolic inflexibility is considered a nidus for NAFLD pathogenesis, causing lipotoxicity,

OPEN ACCESS

Edited by:

Luigi Gnudi,

King's College London,

United Kingdom

Reviewed by:

Saima Ajaz,

King's College Hospital NHS

Foundation Trust, United Kingdom

Annette Schürmann,

German Institute of Human Nutrition

Potsdam-Rehbruecke (DIfE), Germany

*Correspondence:

Arun J. Sanyal

arun.sanyal@vcuhealth.org

Specialty section:

This article was submitted to Translational Endocrinology,

a section of the journal

Frontiers in Endocrinology

Received: 09 February 2021

Accepted: 19 April 2021

Published: 10 May 2021

Citation:

Albhaisi S and Sanyal AJ (2021)

Gene-Environmental Interactions

as Metabolic Drivers of

Nonalcoholic Steatohepatitis.

Front. Endocrinol. 12:665987.

doi: 10.3389/fendo.2021.665987 mitochondrial dysfunction and cellular stress leading to inflammation, apoptosis and fibrogenesis, thus mediating disease progression into nonalcoholic steatohepatitis (NASH) and ultimately cirrhosis. In this review, we describe they key metabolic drivers that contribute to development of NAFLD and NASH, and we explain how NASH is a metabolic disease. Understanding the metabolic basis of $\mathrm{NASH}$ is crucial for the prevention and treatment of this disease.

Keywords: NASH, metabolic syndrome, genes, insulin resistance, lipotoxicity, oxidative stress, inflammation, gut microbiome

\section{INTRODUCTION}

Non-alcoholic fatty liver disease (NAFLD) has become one of the most common causes of chronic liver disease worldwide and is rapidly becoming the most common indication for liver transplantation $(1,2)$. It is a major public health problem of growing prevalence globally paralleling the increase in the prevalence of obesity. NAFLD is often a progressive disease associated with multifaceted deleterious impact and significant complications such as cirrhosis, end-stage liver disease, hepatocellular carcinoma (HCC), and increased overall mortality (3). Nonalcoholic steatohepatitis (NASH) is the inflammatory subtype of NAFLD and is associated with steatosis, inflammation, hepatocyte injury, and that can progress to cirrhosis (4). The understanding of the pathophysiology of NASH has evolved substantially. A large body of evidence strongly supports that NAFLD is the hepatic manifestation of the metabolic syndrome, with insulin resistance being the common driving factor (5). It became clear that NAFLD is a complex multisystem disorder with significant clinical and pathogenic heterogeneity. There is a variety of underlying mechanisms for its development, with the dominant driver being alterations in hepatic and extra-hepatic lipid metabolism $(6,7)$. The disease susceptibility and progression are likely attributed to dynamic interactions between genetic and environmental factors (8-10). 
Variations in genetic background have been identified as an underlying etiology for the interindividual variability in the natural history of the disease (11-13). Epigenetic alterations that occur in response to environmental factors also contribute to the development of NAFLD (10). It has been shown that only a proportion of patients develop chronic inflammation (14). Thus, a small subset of patients with NAFLD develop advanced fibrosis or cirrhosis. Overall, only a minority only experience associated liver-related morbidity $(15,16)$. In addition, not all obese individuals will develop NAFLD and, more importantly, NAFLD can develop in non-obese individuals (an entity known as 'Lean NAFLD') (17). Also, several studies indicate strong heritability of hepatic fat content (11). Therefore, there has been an increased focus in the last few years on exploring genetic factors associated with NAFLD.

\section{DIET AND THE EXTRAHEPATIC MILIEU}

Strong evidence has shown that the metabolic basis of NAFLD is a part of a metabolic disease cluster due to its association with obesity, insulin resistance, type 2 diabetes mellitus (T2DM), hyperlipidemia and cardiovascular disease (CVD) (18). Individuals with NAFLD or NASH typically have hepatic and adipose tissue insulin resistance, with hyperinsulinemia demonstrated even in presence of normal glucose tolerance (19-21). High-calorie diets, excessive consumption of sugar and sedentary lifestyle predispose to NAFLD and NASH and have been linked to the development of other components of the metabolic syndrome (22-24). A common feature in the Western diet is increased fat and fructose consumption that is promoting obesity and fatty liver (7). Diet and diet-related adiposity remain a major cause of NAFLD. Diet can impact the development of NAFLD by promoting obesity and excess adipose tissue which can become inflamed (25). It can also alter the intestinal microbiome and alter intestinal permeability thus increasing systemic exposure to microbial products that are normally largely excluded such as endotoxin resulting in activation of the innate immune system and driving a systemic inflammatory state $(26,27)$. Diet can also contribute to the load of free fatty acids to the liver both directly and by promoting insulin resistance (28). Intake of sugars can contribute by both associated glucotoxicity and by serving as a substrate for de novo lipogenesis. Fructose consumption (such as via sugared sweetened beverages) is associated with extensive metabolic dysfunction, including insulin resistance, altered gut microbiota, dysregulated lipid metabolism and hepatic steatosis (29). Fructose further bypasses several regulated steps in hexose metabolism and can directly serve as a substrate for de novo lipogenesis $(30,31)$; this has led to efforts to use ketohexokinase inhibitors as a treatment of NASH (NCT03248882) $(32,33)$.

In contrast, the Mediterranean diet plays a beneficial role in reducing liver fat and improving cardiovascular risk in patients with NAFLD (34). This diet is enriched in n3 and n6 polyunsaturated fatty acids (PUFAs). N3 PUFAs have insulinsensitizing, anti-inflammatory effects and also impact membrane function across many organ systems. They further reduce hypertriglyceridemia and are expected to improve NAFLD. There are however no long term controlled data to support this as a stand-alone approach to managing the patient with NASH. Also, clinical trials of n3 PUFAs have been disappointing (35). Whether the benefits of such a diet are realized only in the context of the Mediterranean or Ikaria lifestyle or in all settings remains to be established. Further, this diet as all other diets must be considered in the relevant social-cultural context.

Metabolic flexibility refers to the body's ability to adequately handle substrates and maintain energy homeostasis (Figure 1) (36). The inability to handle substrates and calories appropriately is referred to as metabolic inflexibility which tips the energy balance scale towards higher intake and storage, leading to lipotoxic cell stress. Metabolic inflexibility has been recognized as a driving factor for dysregulation of energy homeostasis typically seen in NAFLD/NASH and contributes to dysregulated glucose and lipid metabolism resulting in insulin resistance and dyslipidemia (37). The persistently high intake of sugar and fat on a background of obesity and insulin resistance results in the inability to store free fatty acids (FFAs) in the adipose tissue in addition to increased triglycerides (TG) lipolysis into FFAs. The muscle responds by reducing fat and glucose oxidation.

The resultant high influx of FFAs to the liver combined with increased de novo lipogenesis leads to lipotoxic stress. The process of conversion of FFAs to TG within hepatocytes inhibits peroxisome proliferator-activated receptor- $\alpha$ (PPAR $\alpha)$ signalling (38) and thus maintaining intrahepatic FFA accumulation. Other key signalling pathways mediated by cJun NH2-terminal kinase (JNK) (39), toll-like receptors (TLR4) (40) and novel protein kinase C isoform PKCe (41) exacerbate hepatic insulin resistance leading to a vicious cycle of increased FFA, TG accumulation and formation of toxic lipid species that cause cellular stress (42-44). Overall, these processes contribute to high circulating insulin levels and FFA and inappropriate fat deposition. The hyperinsulinemia and lipotoxic stress act as key triggers for the development of NAFLD. Presence of metabolic syndrome, T2DM and other factors can further heighten the impact of insulin resistance and lipotoxicity which consequently impair the repair response of the liver resulting in progression of the disease $(44,45)$.

\section{THE MICROBIOME AS A DRIVER OF DYSMETABOLIC STATE}

There is growing body of evidence supporting the role of gut microbiome in the development and progression of NAFLD (Table 1) (52, 53). Quantitative and qualitative alterations of gut microbiota composition (also known as 'Dysbiosis') have been recognized in patients with NAFLD and NASH. Instances of gut microbiota producing hepatotoxic substances such as ethanol which alter gut permeability and thus inducing endotoxemia secondary to translocation of bacterial products have been reported $(54,55)$. Patients with NASH tend to have increased levels of circulating endotoxins that can activate innate immune 


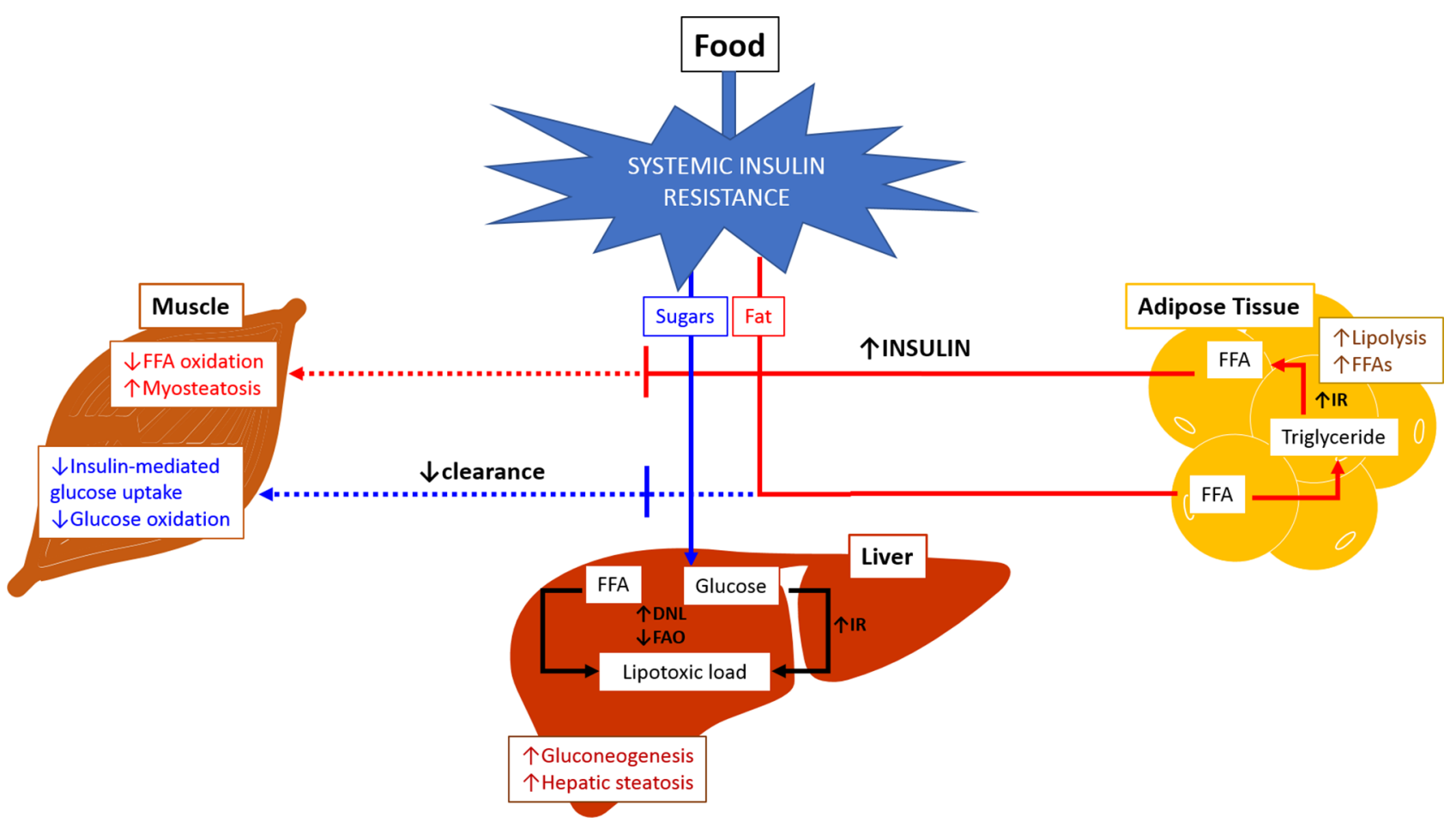

FIGURE 1 | Metabolic Inflexibility. In physiological conditions, fasting state is associated with relatively low insulin levels leading to increased lipolysis and free fatty acid oxidation in adipose tissue and muscles. Glucose oxidation increased in muscles, and gluconeogenesis is activated in the liver. During fed state, food intake increases insulin release which subsequently stimulates lipogenesis and triglyceride accumulation in adipose tissue. There is increase in glucose and free fatty acid oxidation in muscles, and inhibition of gluconeogenesis in the liver. Inability of the body to maintain this balance or to adequately handle substrates at appropriate times is referred to as metabolic inflexibility. The liver loses its ability to flexibly switch back and forth between prandial and fasting states due to exacerbated insulin resistance (hallmark of NAFLD/NASH). Metabolic inflexibility is associated with hyperinsulinemia, systemic lipotoxic cell stress leading to inflammation and fibrogenesis, and eventually NASH. (Adapted from Chakravarthy MV, Siddiqui MS, Forsgren MF and Sanyal AJ (2020), Harnessing Muscle-Liver Crosstalk to Treat Nonalcoholic Steatohepatitis. Front. Endocrinol. 11:592373. doi: 10.3389/fendo.2020.592373.). DNL, de novo lipogenesis; FAO, fatty acid oxidation; FFA, free fatty acid; IR, insulin resistance.

TABLE 1 | Examples of human studies on the gut microbiota-derived metabolites in NAFLD and NASH.

\begin{tabular}{|c|c|c|c|c|}
\hline Study & Subjects & $\begin{array}{c}\text { Type of } \\
\text { metabolites }\end{array}$ & $\begin{array}{l}\text { Type of } \\
\text { sample }\end{array}$ & Results \\
\hline $\begin{array}{l}\text { Loomba } \\
\text { et al. (46) }\end{array}$ & Adults with NAFLD $(n=86)$ & $\begin{array}{l}\text { Short Chain } \\
\text { Fatty Acids }\end{array}$ & Blood & 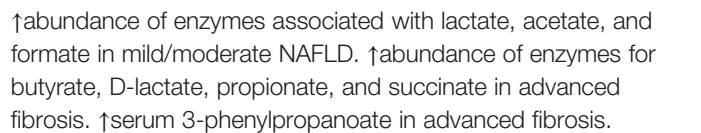 \\
\hline $\begin{array}{l}\text { Hoyles et al. } \\
(47)\end{array}$ & Morbidly obese women $(n=105)$ & Amino Acids & Blood & $\uparrow$ Phenylacetic acid, $\uparrow$ Valine, $\uparrow$ Leucine, $\uparrow$ Isoleucine \\
\hline $\begin{array}{l}\text { Mouzaki } \\
\text { et al. (48) }\end{array}$ & $\begin{array}{l}\text { Adults with NASH }(n=22) \text {, SS }(n=11) \text {, healthy } \\
\text { controls }(n=17)\end{array}$ & Bile Acids & Fecal & $\uparrow$ Primary to secondary BA ratio in $\mathrm{NASH}$ \\
\hline $\begin{array}{l}\text { Raman et al. } \\
\text { (49) }\end{array}$ & Adults with NAFLD $(n=30)$, healthy controls $(n=30)$ & $\begin{array}{l}\text { Ethanol, } \\
\text { vOCs }\end{array}$ & Fecal & $\begin{array}{l}\uparrow \text { Butanoic acid, } \uparrow \text { Propanoic acid, } \uparrow \text { Acetic acid, and } \downarrow 2 \text {-butanone } \\
\text { in NAFLD vs. healthy controls }\end{array}$ \\
\hline $\begin{array}{l}\text { Da Silva } \\
\text { et al. (50) }\end{array}$ & $\begin{array}{l}\text { Adults with SS }(n=15) \text {, NASH }(n=24) \text {, healthy } \\
\text { controls }(n=28)\end{array}$ & $\begin{array}{l}\text { Short Chain } \\
\text { Fatty Acids }\end{array}$ & $\begin{array}{l}\text { Fecal and } \\
\text { Blood }\end{array}$ & $\begin{array}{l}\text { (Fecal) } \uparrow \text { Isobutyric acid, } \uparrow \text { Propionate (Serum) } \uparrow 2 \text {-hydroxy-butyrate, } \\
\uparrow L \text {-lactic acid }\end{array}$ \\
\hline $\begin{array}{l}\text { Del Chierico } \\
\text { et al. (51) }\end{array}$ & $\begin{array}{l}\text { Children and adolescents }(n=61) \text { with NAFLD, NASH, } \\
\text { or obesity, healthy controls }(n=54)\end{array}$ & VOCs & Blood & $\begin{array}{l}\uparrow 2 \text {-butanone and } \uparrow 1 \text {-pentanol in NAFLD. } \uparrow 2 \text {-butanone and } \uparrow 4 \text { - } \\
\text { methyl-2-pentanone in NASH }\end{array}$ \\
\hline
\end{tabular}

$\uparrow$, increase; $\downarrow$, decrease; NAFLD, nonalcoholic fatty liver disease; NASH, nonalcoholic steatohepatitis; SS, simple steatosis; BA, bile acids; VOC, volatile organic compounds.

responses and consequently exacerbating the disease (56). Circulating pathogen-associated molecular pattern (PAMPs) and damage-associated molecular patterns (DAMPs) activate TLRs within the liver and induce production of pro- inflammatory cytokines and reactive oxygen species and activation of the inflammasome $(57,58)$. Several studies demonstrated that NAFLD was associated with increased Firmicutes/Bacteroidetes ratio and that specific metagenomic 
signatures in the intestinal microbiota are robust predictors of advanced fibrosis associated with NASH (46, 59, 60). Gut microbiota are also implicated in modulating bile acid-related pathways, which sequentially regulate lipid and carbohydrate metabolism as well as energy homeostasis (61). Recently, there has been growing interest in evaluating the influence of human genetic variation and ethnicity in driving gut microbiota diversity (62-64). However, separating the effects of diet on liver health from the effects of diet-induced microbiota changes and its role in driving risk for liver disease, remains challenging. Furthermore, most of the literature has focused on associations and mechanistic studies are now needed to better understand how the microbiome leads to NAFLD and contributes to its progression.

\section{SARCOPENIA AS A DRIVER OF NASH}

Recently, there has been an increased interest in investigating the role of skeletal muscles in the pathogenesis of NAFLD (65). Sarcopenia is a pathological disorder characterized by generalized loss of skeletal muscle mass and strength. Sarcopenia has been recently proposed as an additional risk factor of NAFLD and a contributor to its development and progression, even after adjusting for body mass index and insulin resistance $(66,67)$. What was previously only regarded as part of aging (68) is now recognized as a progressive disease frequently associated with cardiometabolic disorders (69). Studies in Asian populations showed that sarcopenia is associated with the presence and severity of NAFLD $(66,70,71)$. A prospective study in Western population showed that sarcopenia was associated with the severity of fibrosis and steatosis in NAFLD patients, independently of hepatic and metabolic risk factors (72).

It is now recognized that the muscle is a key metabolic organ and buffers the functions of the liver. While its role as an ammonia buffer is well known with the hepatology community, its role in maintaining body composition is less well appreciated. Muscles primarily utilize free fatty acids in the fasted state and are critical for mobilization of fat stores with diet and exercise. In the metabolically inflexible sarcopenic state, it depends on glucose as its principal substrate for energy and switches to protein breakdown when glucose is not available further contributing to sarcopenia. A host of myokines have been described of which myostatin is the best known (73-75). They both modulate muscle mass and also contribute to a systemic inflammatory state. Systemic levels of cytokines such as Tumor Necrosis Factor- $\alpha$ (TNF- $\alpha$ ) and other hepatokines such as Fibroblast growth factor 21 (FGF21) may modulate sarcopenia and muscle function respectively as well. There is thus close cross-talk between the muscles and liver to maintain metabolic homeostasis and its disruption is a key aspect of NAFLD. There are however some caveats in the interpretation of data on muscle structure and function in NAFLD. It is difficult to disentangle the impact of aging on body composition and risk for NAFLD (76), from effects mediated by sarcopenia alone given that aging itself is a risk factor for NAFLD through its association with a decrease in muscle mass, an increase in visceral adiposity, ectopic fat deposition and insulin resistance $(66,67)$, in addition to more exposure with time to risk factors of NAFLD.

\section{METABOLIC FLEXIBILITY AND THE ROLE OF ADIPOSE TISSUE AND MUSCLE}

From a pathophysiological perspective, striated muscles play a key role in metabolic homeostasis (77-79). Under physiological conditions, fasting insulin levels are relatively low (80). This releases adipose tissue from insulin-mediated suppression and promotes lipolysis. The free fatty acids released are taken up in striated muscle and used as a principal source of ATP generation. Following a meal, striated muscles clear the circulating glucose load and the muscle shifts from FFA to glucose as a principal source of ATP generation. At the same time, insulin levels rise and suppress lipolysis. This phenomenon of changing fuel source based on availability is also known as metabolic flexibility. Data suggest a relationship between liver and skeletal muscle steatosis in patients with NAFLD. Myokines are active substances derived from skeletal muscle cell. They include myostatin, irisin, myonectin, and various interleukins (IL-6, IL-7, IL-8, and IL-15) and their dysfunction have been implicated in the disrupted adipose-liver-muscle axis in NAFLD (81). Few studies found that skeletal muscle steatosis increased significantly with increasing stage of NASH (82). Fat accumulation in muscles occurs in the context of ectopic fat accumulation and systemic insulin resistance typically associated with NAFLD (82). In the insulin-resistant state associated with obesity, the insulin levels are high and have less variability from fasted to post prandial state. Insulin resistance allows lipolysis to continue in adipose tissue thus releasing excess FFA. While these can be taken up, they are not fully utilized in muscle resulting in ectopic fat storage in the muscle. Also, glucose clearance by muscle is impaired due to insulin resistance. Together, these generate a greater systemic lipid and glucose load which sets the stage for development of excess adiposity and injury to endorgans. In the liver, this is recognized as NAFLD.

\section{METABOLIC STRESS TO THE LIVER}

Key pathogenic mechanisms driving the progression from hepatic steatosis to NASH include aberrant lipid metabolism, oxidative stress, mitochondrial dysfunction, inflammatory cytokines, immune response and alterations in gut microbiome (83). Lipotoxicity refers to the toxic effects of excessive lipids and lipid derivatives on cells. NAFLD results from delivery of excess FFA and glucose to the liver along with inflammatory cytokines in circulation. Glucose that is not oxidized is converted via de novo lipogenesis in to FFA thus further contributing to the lipid load in the liver. The abundance of FFAs generates cytotoxicity through dysregulation of energy storage homeostasis. Several lipotoxic lipids have been studied, such as FFA, lysophosphatidyl 
Choline (LPC), ceramides, free cholesterol (FC), and bile acids (BAs). Hepatic steatosis observed in NAFLD occurs secondary to the liver's attempt to store FFAs in the form of TGs to accommodate excess in FFAs. Adipose tissue derived FFAs are considered drivers of hepatic lipotoxicity. Lipoapoptosis is a principal feature of NASH that results from failure of hepatocytes to dispose of excess FFAs. Intracellular stress leads to hepatocyte apoptosis via activation of intrinsic and extrinsic pathways. The mechanisms involved in lipotoxicity are organelle dysfunctions including endoplasmic reticulum (ER) stress and mitochondrial permeabilization, JNK-induced toxicity and $\mathrm{BH} 3$ only protein-induced mitochondrial and lysosomal dysfunction (84-88). Those pathways ultimately lead to activation of caspases mediating apoptosis (44). Further, defects in hepatic mitochondrial fatty acid beta-oxidation have been suggested to contribute to hepatic steatosis and progression to NASH (89). Several studies demonstrated that patients with NAFLD have distinct lipidomic signatures (90-92). NAFLD and NASH are associated with accumulation of highly toxic lipid metabolites (e.g. diacylglycerol, ceramides, sphingomyelin) which trigger inflammation and hepatocyte damage $(44,93)$. A comprehensive lipidomic analysis on human liver biopsies revealed decreased activity of fatty acid desaturase 1 (FADS1) which is a key player in accumulating toxic lipids during NASH progression (91). The significant complexity of the lipotoxic milieu should be accounted for by targeted therapeutic approaches $(94,95)$.

\section{ROLE OF GENETICS}

Genetics play a key role across the spectrum of NAFLD pathogenesis $(96,97)$. Variations in genes such as patatin-like phospholipase domain-containing protein 3 (PNPLA3), transmembrane 6 superfamily member 2 (TM6SF2), membrane bound O-acyltransferase domain-containing 7 gene (MBOAT7), glucokinase regulator (GCKR), hydroxysteroid 17-beta dehydrogenase-13 (HSD17B13) have been identified as key modifiers of NAFLD development and progression (8). The role of PNPLA3 gene is discussed in a separate section below. Genetic heterogeneity is involved in various aspects of the disease, namely regulation of energy homeostasis and lipotoxic stress, modulating extracellular matrix production and turnover and controlling inflammation. Studies have shown that genetic variants are implicated in regulating insulin signaling (98), oxidative stress (99), and fibrogenesis (100) thus consequently progression to NASH.

TM6SF2 is a gene involved in hepatic very low-density lipoprotein (VLDL) secretion and lipoprotein metabolism. The rs58542926 C>T polymorphism results in loss of this gene's function or reduction of its hepatic expression, leading to impaired secretion of TG-rich lipoproteins and increased hepatocyte TG content $(96,101)$. Studies have shown that mutated variant of TM6SF2 is associated with development of NAFLD likely through altered hepatic lipid metabolism (102), and higher risk of progression to NASH (103). C-allele is linked with increased cardiometabolic risk (104). A large meta-analysis suggested a correlation between $\mathrm{T}$-allele variant and risk developing T2DM (105). The rs58542926 C $>\mathrm{T}$ polymorphism affects nutrient oxidation, glucose homeostasis, and postprandial lipid metabolism and thus contributes to liver injury in NAFLD (106).

MBOAT7 plays an essential role in the phospholipid remodeling pathway. The rs641738 C>T variant attached to the 3' untranslated region of MBOAT7 is a commonly associated with a decrease in phosphatidylinositol-containing arachidonic acid within the hepatocytes which exacerbates liver fibrosis $(101,107)$. Studies have shown that this MBOAT7 variant is associated with increased risk of NAFLD in Caucasians (108).

GCKR controls de novo lipogenesis by regulating glucose influx into hepatocytes (109). Loss of function of GCKR protein results in greater hepatic fat accumulation (110). A large NAFLD metaanalysis has identified PNPLA3 and GCKR as factors for increased hepatic TG content (111).

\section{PNPLA3 MEDIATED PROGRESSION OF LIVER INJURY AND FIBROSIS}

PNPLA3 gene, also called adiponutrin, was the first major gene associated with NASH $(112,113)$. It is the most replicated modifier of NAFLD pathogenesis in different ethnicities (16). Overall, multiple studies in different populations and diverse ethnicities validated the association between NAFLD and PNPLA3 (Figure 2) (104, 111, 112, 114-116). The $P N P L A 3$ enzyme is found in hepatocytes and adipocytes and plays a role in lipid remodeling in the liver $(108,109,112,117)$. The wild type PNPLA3 has function of TG hydrolase and acetylCoA-independent transacylase, and loss of its function consequently leads to an accumulation of triglycerides and retinyl esters within hepatocytes (118). Studies have shown that loss of function of PNPLA3 leads to increased hepatic steatosis and elevated serum alanine aminotransferase (ALT) and aspartate aminotransferase (AST) levels $(102,119)$. Patients with NAFLD who carry the PNPLA3 rs738409 C/G mutation, a genetic polymorphism characterized by the substitution of isoleucine to methionine at position 148 (I148M), are more likely to develop steatohepatitis and fibrosis (16), and this nonsynonymous variant is the main genetic risk factor for disease severity and progression (Figure 3) (120, 121). Studies consistently showed a strong association between I148M and hepatocellular TG accumulation, increased fibrosis and severity of steatohepatitis $(113,122,123)$.

The original studies on mechanisms by which the PNPLA3 I148M variant led to NASH and fibrosis focused on its function as a triglyceride lipase and the loss of function with this mutation (112). This explained the accumulation of triglyceride but did not explicitly explain how this led to steatohepatitis and fibrosis. Elegant studies by Dr. Hobbs and colleagues further established that with increasing mutant gene expression level, there is an abnormal ubiquitination of the mutant protein with less proteosomal degradation leading to accumulation of the protein on the surface of lipid droplets where its loss of function as a triglyceride lipase further contributed to accumulation of triglyceride in the liver $(119,124)$. This too 


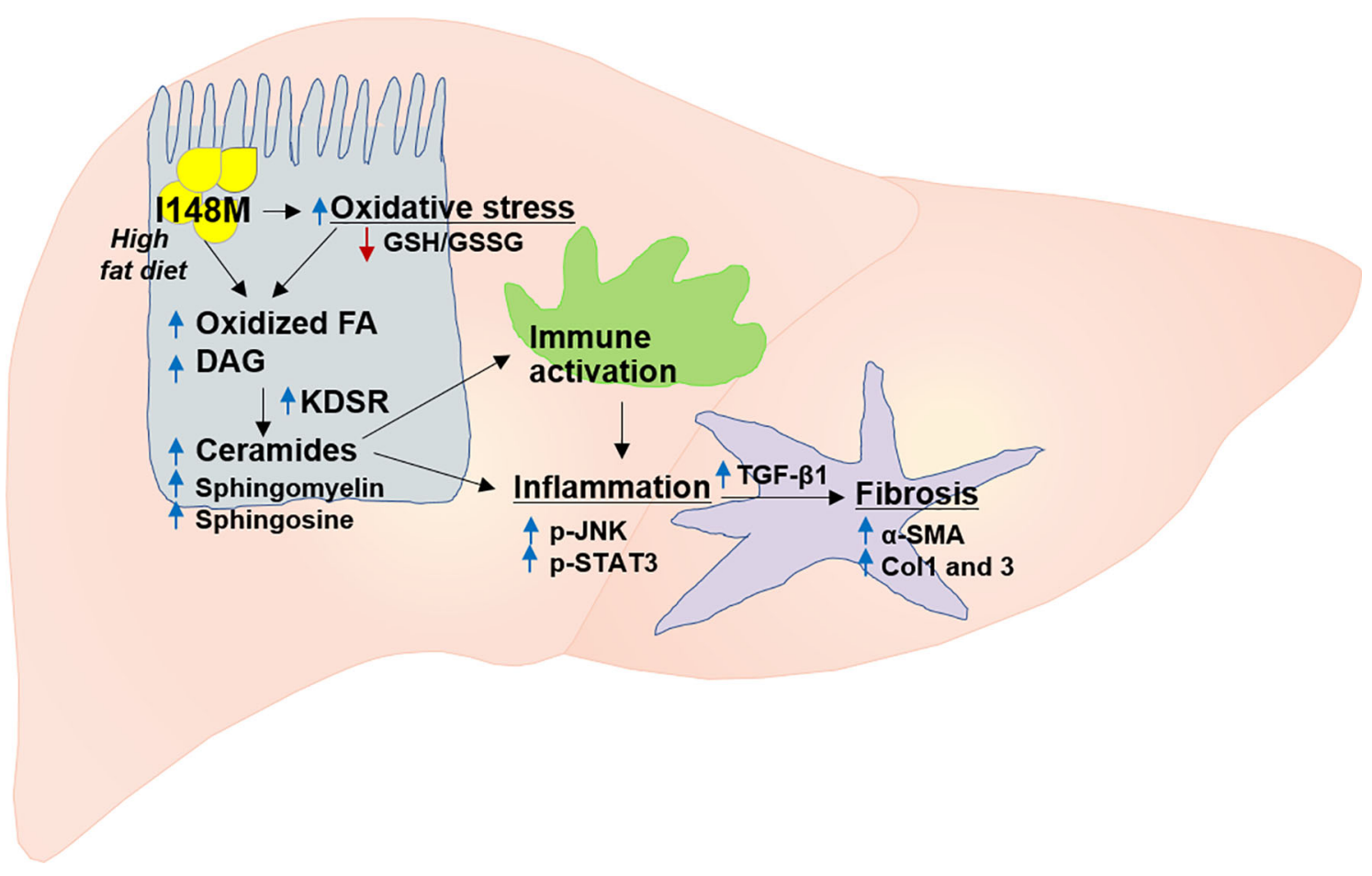

FIGURE 2 | The contribution of mutant PNPLA3 to the risk of NASH and fibrosis. PNPLA3 mutation results in increased oxidative stress and fatty acid oxidation which subsequently leads to accumulation of highly toxic lipid metabolites (e.g. diacylglycerol, ceramides, sphingomyelin, sphingosine). These lipotoxic metabolites trigger immune activation and inflammation via key signaling pathways mediated by $\mathrm{p}$-JNK and p-STAT3, and ultimately activation of several fibrogenic pathways such as those for TGF- $\beta 1, \alpha$-SMA, Col1 and 3. Col1, collagen I; Col3, collagen III; FA, fatty acid; DAG, diacylglycerol; GSH, GSSG, glutathione-disulfide; glutathione; JNK, c-Jun activated kinase; KDSR, 3-ketodihydrosphingosine reductase; SMA, $\alpha$-smooth muscle actin; STAT3, signal transducer and activator of transcription, TGF- $\beta$, transforming growth factor $\beta$.

does not explain the development of steatohepatitis or fibrosis seen in those with this mutation.

Recently, expression of PNPLA3 I148M in stellate cells has been related to increased collagen synthesis $(125,126)$. However, the very low prevalence of significant disease in lean metabolically healthy individuals who carry this mutation makes it unlikely that this alone is enough to explain the impact of this mutation in terms of public health and under conditions of overweight or obesity, those with the mutation appear to have more aggressive fibrosis. A key methodological barrier to studying this question has been the inability to accelerate fibrosis and NASH in a murine model. Whereas silencing PNPLA3 does not lead to a disease phenotype (127), overexpression of the mutant PNPLA3-148M variant generally has accelerated steatosis and some inflammation but not steatohepatitis with fibrosis.

As demonstrated by several studies, the mechanism seems related to accumulation of PNPLA3-148M on lipid droplets as the $148 \mathrm{M}$ variant disrupts ubiquitylation and proteasomal degradation of PNPLA3 and inhibits other lipases, resulting in impaired mobilization of TG from lipid droplets $(119,124)$. Animal models showed that PNPLA3 deletion has no phenotype (128), whereas overexpression or knock-in of the I148M mutation in mice results in increased susceptibility to hepatic fat accumulation (129). A recent study demonstrated that hepatic TG content was associated with significant increase in the PNPLA3-I148M (130). A more recent study to evaluate mechanisms underlying PNPLA3-I148M induced acceleration of $\mathrm{NASH}$ in a murine model where mice received a Western diet with ad lib administration of sugar in drinking water has revealed that under this type of diet, PNPLA3-I148M overexpression promotes steatosis and NASH. This study used a model where mice on a high fat high glucose/fructose diet sequentially developed steatosis, steatohepatitis and then progressive fibrosis. This sequential development of lesions was leveraged by testing the hypothesis that introduction of the mutant PNPLA3 I148M variant but not the wild type PNPLA3 fed this diet would accelerate the disease and lead to steatohepatitis and fibrosis at a time point where mice with empty vector would only have steatosis. The majority of PNPLA3I148M mice developed severe steatohepatitis with fibrosis ( $\mathrm{p}<$ 0.0001). In addition, PNPLA3-I148M significantly worsened the severity of histological features of NASH including steatosis, hepatocellular ballooning and lobular inflammation $(\mathrm{p}<0.001)$. The principal observation in this study is that the hallmark feature linked to PNPLA3-I148M-induced NASH acceleration is 'metabolic reprogramming' of the liver with increased TGs and diglycerides, $\mathrm{n} 3$ polyunsaturated fatty acids depletion and increased ceramides. PNPLA3-I148M also had a significant impact on several 
A

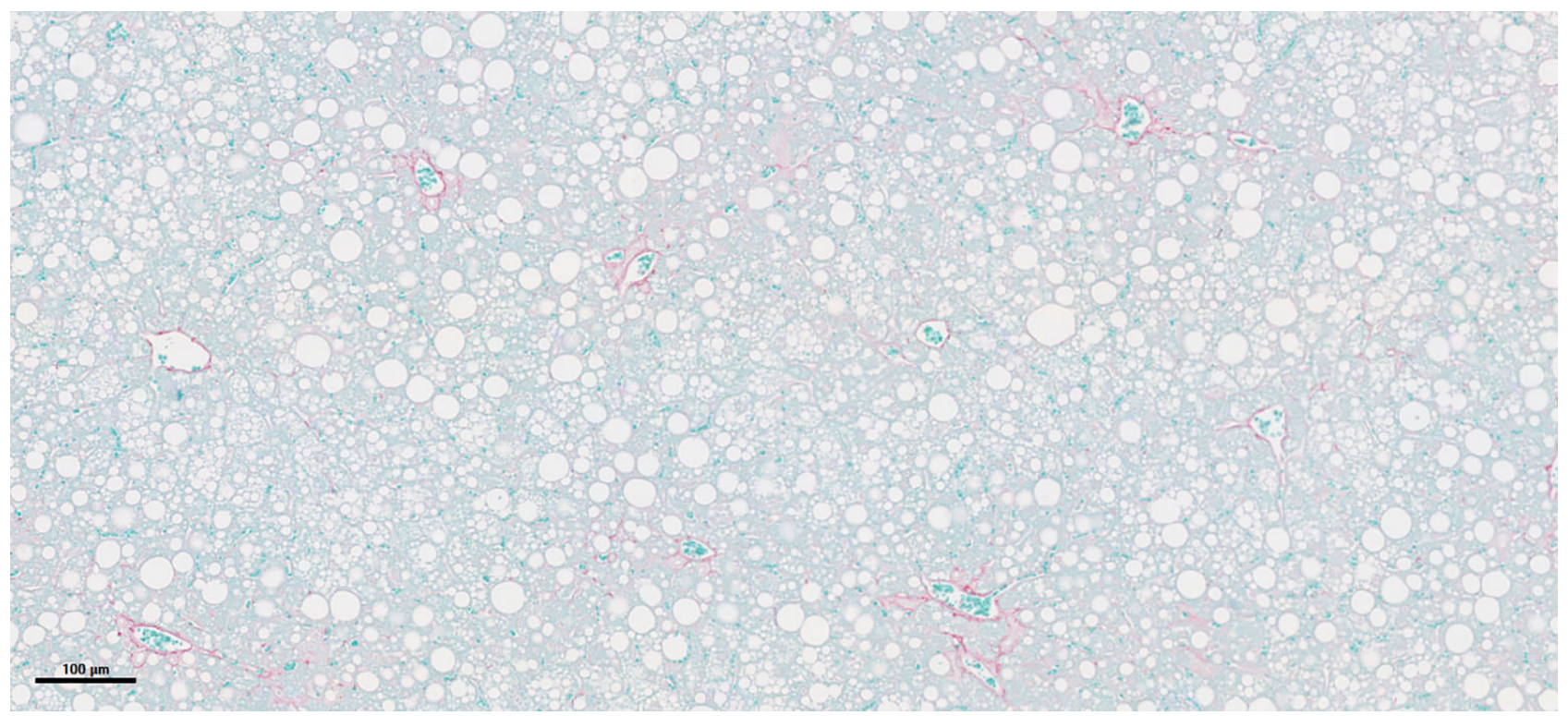

B

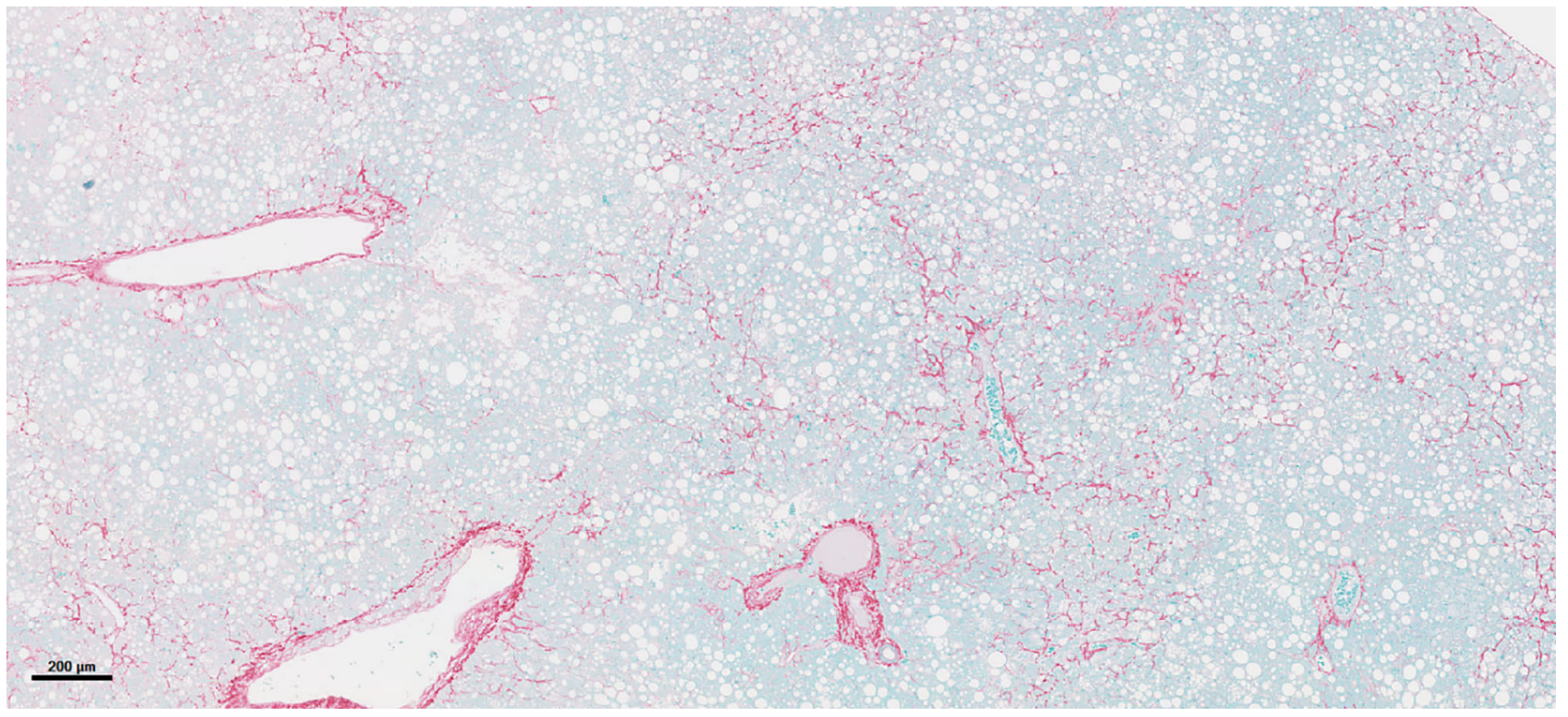

FIGURE 3 | PNPLA3 ${ }^{1448 \mathrm{M}}$-associated acceleration of NASH and fibrosis. (A) Liver histology in mouse of empty vector (Luc) after 16 weeks on a Western diet/sugar water (WDSW) diet with NAFLD with minimal fibrosis. (B) Hepatocyte of mouse with PNPLA3 ${ }^{1148 \mathrm{M}}$ after 16 weeks on a WDSW diet demonstrating NAFLD with advanced bridging fibrosis. (A) 16wks AAV LUC (10x) (B) 16wks PNPLA3 I148M (4x).

cellular processes including proteosomal, phagosomal, and lysosomal function, amino-acyl T RNA synthesis, circadian rhythm and ER function. PNPLA3-I148M expression promoted cell death and increased oxidative stress and ER stress. Multiple inflammatory pathways were activated with PNPLA3-I148M, such as JAK-STAT system. Specifically, the STAT3 system was activated significantly in the presence of the I148M variant. Integrated pathway analysis revealed a strong signature of ceramide related inflammatory activation including h-ras and downstream PLA2 activation, suggesting a key role for sphingolipids in the inflammatory response to PNPLA3-I148M. Furthermore, PNPLA3-I148M was associated with activation of several fibrogenic pathways such as those for Procollagen I, III and $\alpha$ smooth muscle actin mRNA, as well as increased transforming growth factor beta (TGF- $\beta 1$ ) protein levels (131). Importantly, this accelerated phenotype of disease could be rescued by silencing the mutant PNPLA3 I148M variant.

The findings reported in animal models were also supported by human genetic studies which showed that PNPLA3 rs2294918 E434K variant decreased PNPLA3 expression, reducing the effect 
of the I148M variant on the predisposition to steatosis and liver damage (127). This suggests that the PNPLA3 I148M variant expression is required for PNPLA3-associated hepatic steatosis by the aforementioned mechanism. These data suggest that the mutant PNPLA3-I148M protein can be a new therapeutic target for NAFLD and NASH (132).

\section{SUMMARY AND FUTURE DIRECTIONS}

A growing body of literature indicates that the development of the NAFLD phenotype (fatty liver or steatohepatitis) and its progression to cirrhosis represents a complex set of geneenvironment interactions. While environmental factors such as changes in diet play a central role, the role of other factors such as environmental pollutants are also becoming apparent and worthy of further investigation.

The role of genetics in modulating the metabolic drivers of $\mathrm{NASH}$ will be a major area of research over the next decade. Following the landmark studies identifying a linkage between the $\mathrm{I}^{148} \mathrm{M}$ variant of PNPLA3 and progressive NASH, an increasing number of genetic variants have also been linked to the disease. However, for several of these the specific mechanisms by which they affect NASH have not been clarified. Particularly the HSD17B13 splice variant which has a protective role is an important new discovery and future studies will be needed to define how it contributes to the disease and even potentially negates some of the deleterious effects of the PNPLA3 mutation.

It is further clear that individual mutations can not only have an impact based on their biological effect but multiple mutations in different genes in various metabolic pathways can interact to modulate the metabolic response to the lipotoxic load being delivered to the liver. Development of a rigorously validated polygenic risk score remains an important unmet need in the field.

A key focus of this manuscript has been the growing body of literature on the role of the extrahepatic milieu as a cause of the liver disease. Much more work needs to be done on the relationship between changes in diet and the changes in intestinal epithelium and how these alter the meal stimulated gut hormonal response. This is likely to be a key modulator of the state of metabolism and the development of both the metabolic syndrome and fatty liver disease. Early data from the metabolic benefits of duodenal mucosal resurfacing provide a strong rationale to continue to pursue this line of research. These are

\section{REFERENCES}

1. Younossi Z, Anstee QM, Marietti M, Hardy T, Henry L, Eslam M, et al. Global Burden of NAFLD and NASH: Trends, Predictions, Risk Factors and Prevention. Nat Rev Gastroenterol Hepatol (2018) 15:11-20. doi: 10.1038/ nrgastro.2017.109

2. Younossi ZM, Koenig AB, Abdelatif D, Fazel Y, Henry L, Wymer M. Global Epidemiology of Nonalcoholic Fatty Liver disease-Meta-analytic Assessment of Prevalence, Incidence, and Outcomes. Hepatol Baltim Md (2016) 64:73-84. doi: 10.1002/hep.28431

3. Younossi ZM, Blissett D, Blissett R, Henry L, Stepanova M, Younossi Y, et al. The Economic and Clinical Burden of Nonalcoholic Fatty Liver Disease in also likely to yield potential therapeutic approaches beyond duodenal mucosal surfacing.

The role of the intestinal microbiome continues to be elucidated as well. There is already a plethora of literature demonstrating changes in specific taxa that are linked to the NASH and even advanced fibrosis. While some data on metagenomics are available, they are not tightly concordant with the metabolomic signatures in stool and direct interrogation of the microbial transcriptome will be needed to better understand the role of altered microbial taxa in NASH. Further functional analyses of changes in the microbiome will provide mechanistic insights into the nature of microbial contribution to the disease and its progression. It will also set the stage for phase-based therapeutics for NASH.

Additional intestinal factors such as secondary bile acids are likely to also be important. Many bacteria are susceptible to the antibiotic functions of secondary bile acids and decrease when secondary bile acids increase whereas bacteria that require such bile acids for growth increase. These may provide a potential explanation for the changes in microbial composition. Further systemic uptake of secondary bile acids may have direct effects on metabolism via FXR, TGR5 and affect processes such as senescence to cause hepatocellular cancer.

Finally, the importance of striated muscle and adipose tissue in driving $\mathrm{NASH}$ is also becoming apparent and direct modification of muscle function by specifically engineered diets designed to break metabolic inflexibility to improve the systemic metabolic state are likely to improve not only NAFLD but the systemic state of dysmetabolism.

In summary, while much progress has been made in understanding the metabolic drivers of NASH, much additional work remains to be done. These are likely to have a major impact on the understanding of the role of the systemic changes in metabolic syndrome and how these lead to NASH. Geneenvironmental interactions and studies to define subpopulations based on clustering of specific genetic and environmental factors may provide insights on the heterogeneity of NAFLD and new approaches to treat individual patients.

\section{AUTHOR CONTRIBUTIONS}

Both authors contributed to the writing of the manuscript. All authors contributed to the article and approved the submitted version.

the United States and Europe. Hepatology (2016) 64:1577-86. doi: 10.1002/ hep. 28785

4. Chalasani N, Younossi Z, Lavine JE, Charlton M, Cusi K, Rinella M, et al. The Diagnosis and Management of Nonalcoholic Fatty Liver Disease: Practice Guidance From the American Association for the Study of Liver Diseases. Hepatol Baltim Md (2018) 67:328-57. doi: 10.1002/hep.29367

5. Marchesini G, Marzocchi R, Agostini F, Bugianesi E. Nonalcoholic Fatty Liver Disease and the Metabolic Syndrome. Curr Opin Lipidol (2005) 16:421-7. doi: 10.1097/01.mol.0000174153.53683.f2

6. Deprince A, Haas JT, Staels B. Dysregulated Lipid Metabolism Links NAFLD to Cardiovascular Disease. Mol Metab (2020) 42. doi: 10.1016/ j.molmet.2020.101092 
7. Eslam M, Sanyal AJ, George J, Sanyal A, Neuschwander-Tetri B, Tiribelli C, et al. Mafld: A Consensus-Driven Proposed Nomenclature for Metabolic Associated Fatty Liver Disease. Gastroenterology (2020) 158:1999-2014.e1. doi: 10.1053/j.gastro.2019.11.312

8. Eslam M, George J. Genetic and Epigenetic Mechanisms of NASH. Hepatol Int (2016) 10:394-406. doi: 10.1007/s12072-015-9689-y

9. Buzzetti E, Pinzani M, Tsochatzis EA. The Multiple-Hit Pathogenesis of non-Alcoholic Fatty Liver Disease (NAFLD). Metabolism (2016) 65:103848. doi: 10.1016/j.metabol.2015.12.012

10. Jonas W, Schürmann A. Genetic and Epigenetic Factors Determining NAFLD Risk. Mol Metab (2020) 101111. doi: 10.1016/j.molmet.2020.101111

11. Dongiovanni P, Anstee QM, Valenti L. Genetic Predisposition in NAFLD and NASH: Impact on Severity of Liver Disease and Response to Treatment. Curr Pharm Des (2013) 19:5219-38. doi: 10.2174/13816128 113199990381

12. Liu Y-L, Reeves HL, Burt AD, Tiniakos D, McPherson S, Leathart JBS, et al. Tm6sf2 rs58542926 Influences Hepatic Fibrosis Progression in Patients With non-Alcoholic Fatty Liver Disease. Nat Commun (2014) 5:4309. doi: $10.1038 /$ ncomms 5309

13. Trépo E, Valenti L. Update on NAFLD Genetics: From New Variants to the Clinic. J Hepatol (2020) 72:1196-209. doi: 10.1016/j.jhep.2020.02.020

14. Serfaty L, Lemoine M. Definition and Natural History of Metabolic Steatosis: Clinical Aspects of NAFLD, NASH and Cirrhosis. Diabetes Metab (2008) 34:634-7. doi: 10.1016/S1262-3636(08)74597-X

15. Singh S, Allen AM, Wang Z, Prokop LJ, Murad MH, Loomba R. Fibrosis Progression in Nonalcoholic Fatty Liver Versus Nonalcoholic Steatohepatitis: A Systematic Review and Meta-analysis of Paired-Biopsy Studies. Clin Gastroenterol Hepatol (2015) 13:643-54.e9. doi: 10.1016/ j.cgh.2014.04.014

16. Anstee QM, Day CP. The Genetics of Nonalcoholic Fatty Liver Disease: Spotlight on PNPLA3 and TM6SF2. Semin Liver Dis (2015) 35:270-90. doi: 10.1055/s-0035-1562947

17. Albhaisi S, Chowdhury A, Sanyal AJ. Non-Alcoholic Fatty Liver Disease in Lean Individuals. JHEP Rep Innov Hepatol (2019) 1:329-41. doi: 10.1016/ j.jhepr.2019.08.002

18. Paschos P, Paletas K. Non Alcoholic Fatty Liver Disease and Metabolic Syndrome. Hippokratia (2009) 13:9-19.

19. Marchesini G, Brizi M, Morselli-Labate AM, Bianchi G, Bugianesi E, McCullough AJ, et al. Association of Nonalcoholic Fatty Liver Disease With Insulin Resistance. Am J Med (1999) 107:450-5. doi: 10.1016/S00029343(99)00271-5

20. Sanyal AJ, Campbell-Sargent C, Mirshahi F, Rizzo WB, Contos MJ, Sterling RK, et al. Nonalcoholic Steatohepatitis: Association of Insulin Resistance and Mitochondrial Abnormalities. Gastroenterology (2001) 120:1183-92. doi: 10.1053/gast.2001.23256

21. Portillo-Sanchez P, Bril F, Maximos M, Lomonaco R, Biernacki D, Orsak B, et al. High Prevalence of Nonalcoholic Fatty Liver Disease in Patients With Type 2 Diabetes Mellitus and Normal Plasma Aminotransferase Levels. J Clin Endocrinol Metab (2015) 100:2231-8. doi: 10.1210/ jc.2015-1966

22. Jensen T, Abdelmalek MF, Sullivan S, Nadeau KJ, Green M, Roncal C, et al. Fructose and Sugar: A Major Mediator of non-Alcoholic Fatty Liver Disease. J Hepatol (2018) 68:1063-75. doi: 10.1016/j.jhep.2018.01.019

23. Gerber L, Otgonsuren M, Mishra A, Escheik C, Birerdinc A, Stepanova M, et al. Non-Alcoholic Fatty Liver Disease (NAFLD) is Associated With Low Level of Physical Activity: A Population-Based Study. Aliment Pharmacol Ther (2012) 36:772-81. doi: 10.1111/apt.12038

24. Kechagias S, Ernersson A, Dahlqvist O, Lundberg P, Lindström T, Nystrom $\mathrm{FH}$, et al. Fast-Food-Based Hyper-Alimentation can Induce Rapid and Profound Elevation of Serum Alanine Aminotransferase in Healthy Subjects. Gut (2008) 57:649-54. doi: 10.1136/gut.2007.131797

25. Fabbrini E, Sullivan S, Klein S. Obesity and Nonalcoholic Fatty Liver Disease: Biochemical, Metabolic and Clinical Implications. Hepatol Baltim Md (2010) 51:679-89. doi: 10.1002/hep.23280

26. Massier L, Chakaroun R, Tabei S, Crane A, Didt KD, Fallmann J, et al. Adipose Tissue Derived Bacteria are Associated With Inflammation in Obesity and Type 2 Diabetes. Gut (2020) 69:1796-806. doi: 10.1136/ gutjnl-2019-320118
27. Camilleri M, Lyle BJ, Madsen KL, Sonnenburg J, Verbeke K, Wu GD. Role for Diet in Normal Gut Barrier Function: Developing Guidance Within the Framework of Food-Labeling Regulations. Am J Physiol - Gastrointest Liver Physiol (2019) 317:G17-39. doi: 10.1152/ajpgi.00063.2019

28. Sears B, Perry M. The Role of Fatty Acids in Insulin Resistance. Lipids Health Dis (2015) 14. doi: 10.1186/s12944-015-0123-1

29. Romero-Gómez M, Zelber-Sagi S, Trenell M. Treatment of NAFLD With Diet, Physical Activity and Exercise. J Hepatol (2017) 67:829-46. doi: 10.1016/j.jhep.2017.05.016

30. Ter Horst KW, Serlie MJ. Fructose Consumption, Lipogenesis, and NonAlcoholic Fatty Liver Disease. Nutrients (2017) 9(9):81. doi: 10.3390/ nu9090981

31. Hannou SA, Haslam DE, McKeown NM, Herman MA. Fructose metabolism and metabolic disease. J Clin Invest (2018) 128:545-55. doi: 10.1172/ JCI96702

32. Shepherd EL, Saborano R, Northall E, Matsuda K, Ogino H, Yashiro H, et al. Ketohexokinase Inhibition Improves NASH by Reducing Fructose-Induced Steatosis and Fibrogenesis. JHEP Rep (2020) 3. doi: 10.1016/ j.jhepr.2020.100217

33. Futatsugi K, Smith AC, Tu M, Raymer B, Ahn K, Coffey SB, et al. Discovery of PF-06835919: A Potent Inhibitor of Ketohexokinase (KHK) for the Treatment of Metabolic Disorders Driven by the Overconsumption of Fructose. J Med Chem (2020) 63:13546-60. doi: 10.1021/ acs.jmedchem.0c00944

34. Trovato FM, Catalano D, Martines GF, Pace P, Trovato GM. Mediterranean Diet and non-Alcoholic Fatty Liver Disease: The Need of Extended and Comprehensive Interventions. Clin Nutr (2015) 34:86-8. doi: 10.1016/ j.clnu.2014.01.018

35. Sanyal AJ, Abdelmalek MF, Suzuki A, Cummings OW, Chojkier M. No Significant Effects of Ethyl-Eicosapentanoic Acid on Histologic Features of Nonalcoholic Steatohepatitis in a Phase 2 Trial. Gastroenterology (2014) 147:377-84.el. doi: 10.1053/j.gastro.2014.04.046

36. Galgani JE, Moro C, Ravussin E. Metabolic Flexibility and Insulin Resistance. Am J Physiol Endocrinol Metab (2008) 295:E1009-1017. doi: 10.1152/ajpendo.90558.2008

37. Chakravarthy MV, Neuschwander-Tetri BA. The Metabolic Basis of Nonalcoholic Steatohepatitis. Endocrinol Diabetes Metab (2020) 3:e00112. doi: $10.1002 / \mathrm{edm} 2.112$

38. Chakravarthy MV, Pan Z, Zhu Y, Tordjman K, Schneider JG, Coleman T, et al. "New" Hepatic Fat Activates PPARalpha to Maintain Glucose, Lipid, and Cholesterol Homeostasis. Cell Metab (2005) 1:309-22. doi: 10.1016/ j.cmet.2005.04.002

39. Seki E, Brenner DA, Karin M. A Liver Full of JNK: Signaling in Regulation of Cell Function and Disease Pathogenesis, and Clinical Approaches. Gastroenterology (2012) 143:307-20. doi: 10.1053/j.gastro.2012.06.004

40. Holland WL, Bikman BT, Wang L-P, Yuguang G, Sargent KM, Bulchand S, et al. Lipid-Induced Insulin Resistance Mediated by the Proinflammatory Receptor TLR4 Requires Saturated Fatty Acid-Induced Ceramide Biosynthesis in Mice. J Clin Invest (2011) 121:1858-70. doi: 10.1172/ JCI43378

41. Jornayvaz FR, Shulman GI. Diacylglycerol Activation of Protein Kinase Ce and Hepatic Insulin Resistance. Cell Metab (2012) 15:574-84. doi: 10.1016/ j.cmet.2012.03.005

42. Kumashiro N, Erion DM, Zhang D, Kahn M, Beddow SA, Chu X, et al. Cellular Mechanism of Insulin Resistance in Nonalcoholic Fatty Liver Disease. Proc Natl Acad Sci USA (2011) 108:16381-5. doi: 10.1073/pnas. 1113359108

43. Magkos F, Su X, Bradley D, Fabbrini E, Conte C, Eagon JC, et al. Intrahepatic Diacylglycerol Content is Associated With Hepatic Insulin Resistance in Obese Subjects. Gastroenterology (2012) 142:1444-6.e2. doi: 10.1053/ j.gastro.2012.03.003

44. Mota M, Banini BA, Cazanave SC, Sanyal AJ. Molecular Mechanisms of Lipotoxicity and Glucotoxicity in Nonalcoholic Fatty Liver Disease. Metabolism (2016) 65:1049-61. doi: 10.1016/j.metabol.2016.02.014

45. Mogler C, Wieland M, König C, Hu J, Runge A, Korn C, et al. Hepatic Stellate Cell-Expressed Endosialin Balances Fibrogenesis and Hepatocyte Proliferation During Liver Damage. EMBO Mol Med (2015) 7:332-8. doi: 10.15252/emmm.201404246 
46. Loomba R, Seguritan V, Li W, Long T, Klitgord N, Bhatt A, et al. Gut Microbiome Based Metagenomic Signature for non-Invasive Detection of Advanced Fibrosis in Human Nonalcoholic Fatty Liver Disease. Cell Metab (2017) 25:1054-62.e5. doi: 10.1016/j.cmet.2017.04.001

47. Hoyles L, Fernández-Real J-M, Federici M, Serino M, Abbott J, Charpentier J, et al. Molecular Phenomics and Metagenomics of Hepatic Steatosis in Non-Diabetic Obese Women. Nat Med (2018) 24:1070-80. doi: 10.1038/ s41591-018-0061-3

48. Mouzaki M, Comelli EM, Arendt BM, Bonengel J, Fung SK, Fischer SE, et al. Intestinal Microbiota in Patients With Nonalcoholic Fatty Liver Disease. Hepatol Baltim Md (2013) 58:120-7. doi: 10.1002/hep.26319

49. Raman M, Ahmed I, Gillevet PM, Probert CS, Ratcliffe NM, Smith S, et al. Fecal Microbiome and Volatile Organic Compound Metabolome in Obese Humans With Nonalcoholic Fatty Liver Disease. Clin Gastroenterol Hepatol Off Clin Pract J Am Gastroenterol Assoc (2013) 11:868-75.e1-3. doi: 10.1016/ j.cgh.2013.02.015

50. Da Silva HE, Teterina A, Comelli EM, Taibi A, Arendt BM, Fischer SE, et al. Nonalcoholic Fatty Liver Disease is Associated With Dysbiosis Independent of Body Mass Index and Insulin Resistance. Sci Rep (2018) 8:1466. doi: 10.1038/s41598-018-19753-9

51. Chierico FD, Nobili V, Vernocchi P, Russo A, Stefanis CD, Gnani D, et al. Gut Microbiota Profiling of Pediatric Nonalcoholic Fatty Liver Disease and Obese Patients Unveiled by an Integrated Meta-Omics-Based Approach. Hepatology (2017) 65:451-64. doi: 10.1002/hep.28572

52. Leung C, Rivera L, Furness JB, Angus PW. The Role of the Gut Microbiota in NAFLD. Nat Rev Gastroenterol Hepatol (2016) 13:412-25. doi: 10.1038/ nrgastro.2016.85

53. Albhaisi SAM, Bajaj JS. The Influence of the Microbiome on NAFLD and NASH. Clin Liver Dis (2021) 17:15-8. doi: 10.1002/cld.1010

54. Albhaisi SAM, Bajaj JS, Sanyal AJ. Role of Gut Microbiota in Liver Disease. Am J Physiol Gastrointest Liver Physiol (2020) 318:G84-98. doi: 10.1152/ ajpgi.00118.2019

55. Minemura M, Shimizu Y. Gut Microbiota and Liver Diseases. World J Gastroenterol (2015) 21:1691-702. doi: 10.3748/wjg.v21.i6.1691

56. Tilg H, Kaser A. Gut Microbiome, Obesity, and Metabolic Dysfunction. J Clin Invest (2011) 121:2126-32. doi: 10.1172/JCI58109

57. Miura K, Ohnishi H. Role of Gut Microbiota and Toll-like Receptors in Nonalcoholic Fatty Liver Disease. World J Gastroenterol (2014) 20:7381-91. doi: 10.3748/wjg.v20.i23.7381

58. Roh YS, Seki E. Toll-Like Receptors in Alcoholic Liver Disease, nonAlcoholic Steatohepatitis and Carcinogenesis. J Gastroenterol Hepatol (2013) 28(Suppl):38-42. doi: 10.1111/jgh.12019

59. Caussy C, Tripathi A, Humphrey G, Bassirian S, Singh S, Faulkner C, et al. A Gut Microbiome Signature for Cirrhosis Due to Nonalcoholic Fatty Liver Disease. Nat Commun (2019) 10:1406. doi: 10.1038/s41467-019-09455-9

60. Caussy C, Hsu C, Lo M-T, Liu A, Bettencourt R, Ajmera VH, et al. Link Between Gut-Microbiome Derived Metabolite and Shared Gene-Effects With Hepatic Steatosis and Fibrosis in NAFLD. Hepatology (2018) 68:918-32. doi: 10.1002/hep.29892

61. Arab JP, Karpen SJ, Dawson PA, Arrese M, Trauner M. Bile Acids and Nonalcoholic Fatty Liver Disease: Molecular Insights and Therapeutic Perspectives. Hepatol Baltim Md (2017) 65:350-62. doi: 10.1002/ hep. 28709

62. Bonder MJ, Kurilshikov A, Tigchelaar EF, Mujagic Z, Imhann F, Vila AV, et al. The Effect of Host Genetics on the Gut Microbiome. Nat Genet (2016) 48:1407-12. doi: 10.1038/ng.3663

63. Hall AB, Tolonen AC, Xavier RJ. Human Genetic Variation and the Gut Microbiome in Disease. Nat Rev Genet (2017) 18:690-9. doi: 10.1038/ nrg.2017.63

64. Brooks AW, Priya S, Blekhman R, Bordenstein SR. Gut Microbiota Diversity Across Ethnicities in the United States. PLoS Biol (2018) 16:e2006842. doi: 10.1371/journal.pbio.2006842

65. Ballestri S, Nascimbeni F, Romagnoli D, Baldelli E, Targher G, Lonardo A. Type 2 Diabetes in Non-Alcoholic Fatty Liver Disease and Hepatitis C Virus Infection-Liver: The "Musketeer" in the Spotlight. Int J Mol Sci (2016) 17 (3):335. doi: 10.3390/ijms17030355

66. Lee Y-H, Jung KS, Kim SU, Yoon H-J, Yun YJ, Lee B-W, et al. Sarcopaenia is Associated With NAFLD Independently of Obesity and Insulin Resistance:
Nationwide Surveys (KNHANES 2008-2011). J Hepatol (2015) 63:486-93. doi: 10.1016/j.jhep.2015.02.051

67. Lee Y, Kim SU, Song K, Park JY, Kim DY, Ahn SH, et al. Sarcopenia is Associated With Significant Liver Fibrosis Independently of Obesity and Insulin Resistance in Nonalcoholic Fatty Liver Disease: Nationwide Surveys (KNHANES 2008-2011). Hepatology (2016) 63:776-86. doi: 10.1002/ hep. 28376

68. Cruz-Jentoft AJ, Landi F, Topinková E, Michel J-P. Understanding Sarcopenia as a Geriatric Syndrome. Curr Opin Clin Nutr Metab Care (2010) 13:1-7. doi: 10.1097/MCO.0b013e328333clc1

69. The Lancet Diabetes Endocrinology Null. Sarcopenia: A Fate Worth Challenging. Lancet Diabetes Endocrinol (2014) 2:183. doi: 10.1016/S22138587(14)70055-5

70. Hong HC, Hwang SY, Choi HY, Yoo HJ, Seo JA, Kim SG, et al. Relationship Between Sarcopenia and Nonalcoholic Fatty Liver Disease: The Korean Sarcopenic Obesity Study. Hepatol Baltim Md (2014) 59:1772-8. doi: 10.1002/hep.26716

71. Koo BK, Kim D, Joo SK, Kim JH, Chang MS, Kim BG, et al. Sarcopenia is an Independent Risk Factor for non-Alcoholic Steatohepatitis and Significant Fibrosis. J Hepatol (2017) 66:123-31. doi: 10.1016/j.jhep.2016.08.019

72. Petta S, Ciminnisi S, Marco VD, Cabibi D, Cammà C, Licata $\mathrm{A}$, et al. Sarcopenia is Associated With Severe Liver Fibrosis in Patients With nonAlcoholic Fatty Liver Disease. Aliment Pharmacol Ther (2017) 45:510-8. doi: 10.1111/apt.13889

73. Eckel J. Chapter 3 - Skeletal Muscle: A Novel Secretory Organ. In: J Eckel, editor. The Cellular Secretome and Organ Crosstalk. Cambridge, Massachusetts, USA: Academic Press (2018). p. 65-90. Available at: https://www.sciencedirect.com/science/article/pii/B9780128095188000039. doi: 10.1016/B978-0-12-809518-8.00003-9

74. Chen W, Wang L, You W, Shan T. Myokines Mediate the Cross Talk Between Skeletal Muscle and Other Organs. J Cell Physiol (2021) 236:2393412. doi: $10.1002 /$ jcp.30033

75. Lee JH, Jun H-S. Role of Myokines in Regulating Skeletal Muscle Mass and Function. Front Physiol (2019) 10. doi: 10.3389/fphys.2019.00042

76. Kuk JL, Saunders TJ, Davidson LE, Ross R. Age-Related Changes in Total and Regional Fat Distribution. Ageing Res Rev (2009) 8:339-48. doi: 10.1016/ j.arr.2009.06.001

77. Jaiswal N, Gavin MG, Quinn WJ, Luongo TS, Gelfer RG, Baur JA, et al. The Role of Skeletal Muscle Akt in the Regulation of Muscle Mass and Glucose Homeostasis. Mol Metab (2019) 28:1-13. doi: 10.1016/j.molmet. 2019.08.001

78. Han J, Kaufman RJ. The Role of ER Stress in Lipid Metabolism and Lipotoxicity. J Lipid Res (2016) 57:1329-38. doi: 10.1194/jlr.R067595

79. Bozaykut P, Sahin A, Karademir B, Ozer NK. Endoplasmic Reticulum Stress Related Molecular Mechanisms in Nonalcoholic Steatohepatitis. Mech Ageing Dev (2016) 157:17-29. doi: 10.1016/j.mad.2016.07.001

80. Wilcox G. Insulin and Insulin Resistance. Clin Biochem Rev (2005) 26:19-39.

81. Altajar S, Baffy G. Skeletal Muscle Dysfunction in the Development and Progression of Nonalcoholic Fatty Liver Disease. J Clin Transl Hepatol (2020) 8:414-23. doi: 10.14218/JCTH.2020.00065

82. Kitajima Y, Hyogo H, Sumida Y, Eguchi Y, Ono N, Kuwashiro T, et al. Severity of non-Alcoholic Steatohepatitis is Associated With Substitution of Adipose Tissue in Skeletal Muscle. J Gastroenterol Hepatol (2013) 28:150714. doi: 10.1111/jgh.12227

83. Bence KK, Birnbaum MJ. Metabolic Drivers of non-Alcoholic Fatty Liver Disease. Mol Metab (2020) 101143. doi: 10.1016/j.molmet.2020.101143

84. Stremmel W, Staffer S, Wannhoff A, Pathil A, Chamulitrat W. Plasma Membrane Phospholipase A2 Controls Hepatocellular Fatty Acid Uptake and is Responsive to Pharmacological Modulation: Implications for Nonalcoholic Steatohepatitis. FASEB J (2014) 28:3159-70. doi: 10.1096/fj.14-249763

85. Pan X, Wang P, Luo J, Wang Z, Song Y, Ye J, et al. Adipogenic Changes of Hepatocytes in a High-Fat Diet-Induced Fatty Liver Mice Model and nonAlcoholic Fatty Liver Disease Patients. Endocrine (2015) 48:834-47. doi: 10.1007/s12020-014-0384-x

86. Chabowski A, Żendzian-Piotrowska M, Konstantynowicz K, Pankiewicz W, Mikłosz A, Łukaszuk B, et al. Fatty Acid Transporters Involved in the Palmitate and Oleate Induced Insulin Resistance in Primary Rat Hepatocytes. Acta Physiol (2013) 207:346-57. doi: 10.1111/apha.12022 
87. Lewis GF, Carpentier A, Adeli K, Giacca A. Disordered Fat Storage and Mobilization in the Pathogenesis of Insulin Resistance and Type 2 Diabetes. Endocr Rev (2002) 23:201-29. doi: 10.1210/edrv.23.2.0461

88. Cambri LT, Ghezzi AC, Arsa G, Botezelli JD, de Mello MA. Standard ShortTerm Diet Ameliorates the Lipid Profile Altered by a Fructose-Rich Diet in Rats. J Dev Orig Health Dis (2015) 6:335-41. doi: 10.1017/ S2040174415001026

89. Wei Y, Rector RS, Thyfault JP, Ibdah JA. Nonalcoholic Fatty Liver Disease and Mitochondrial Dysfunction. World J Gastroenterol WJG (2008) 14:1939. doi: $10.3748 /$ wjg. 14.193

90. Barr J, Caballería J, Martínez-Arranz I, Domínguez-Díez A, Alonso C, Muntané J, et al. Obesity-Dependent Metabolic Signatures Associated With Nonalcoholic Fatty Liver Disease Progression. J Proteome Res (2012) 11:2521-32. doi: 10.1021/pr201223p

91. Chiappini F, Coilly A, Kadar H, Gual P, Tran A, Desterke C, et al. Metabolism Dysregulation Induces a Specific Lipid Signature of Nonalcoholic Steatohepatitis in Patients. Sci Rep (2017) 7:46658. doi: $10.1038 /$ srep 46658

92. Loomba R, Quehenberger O, Armando A, Dennis EA. Polyunsaturated Fatty Acid Metabolites as Novel Lipidomic Biomarkers for Noninvasive Diagnosis of Nonalcoholic Steatohepatitis. J Lipid Res (2015) 56:185-92. doi: 10.1194/ jlr.P055640

93. Hirsova P, Ibrahim SH, Gores GJ, Malhi H. Lipotoxic Lethal and Sublethal Stress Signaling in Hepatocytes: Relevance to NASH Pathogenesis. J Lipid Res (2016) 57:1758-70. doi: 10.1194/jlr.R066357

94. Cohen JC, Horton JD, Hobbs HH. Human Fatty Liver Disease: Old Questions and New Insights. Science (2011) 332:1519-23. doi: 10.1126/ science. 1204265

95. Cusi K. Role of Obesity and Lipotoxicity in the Development of Nonalcoholic Steatohepatitis: Pathophysiology and Clinical Implications. Gastroenterology (2012) 142:711-25.e6. doi: 10.1053/j.gastro.2012.02.003

96. Severson TJ, Besur S, Bonkovsky HL. Genetic Factors That Affect Nonalcoholic Fatty Liver Disease: A Systematic Clinical Review. World J Gastroenterol (2016) 22:6742-56. doi: 10.3748/wjg.v22.i29.6742

97. Sookoian S, Pirola CJ. Nonalcoholic Fatty Liver Disease and Metabolic Syndrome: Shared Genetic Basis of Pathogenesis. Hepatol Baltim Md (2016) 64:1417-20. doi: 10.1002/hep.28746

98. Dongiovanni P, Valenti L, Rametta R, Daly AK, Nobili V, Mozzi E, et al. Genetic Variants Regulating Insulin Receptor Signalling are Associated With the Severity of Liver Damage in Patients With non-Alcoholic Fatty Liver Disease. Gut (2010) 59:267-73. doi: 10.1136/gut.2009.190801

99. Valenti L, Canavesi E, Galmozzi E, Dongiovanni P, Rametta R, Maggioni P, et al. Beta-Globin Mutations are Associated With Parenchymal Siderosis and Fibrosis in Patients With non-Alcoholic Fatty Liver Disease. J Hepatol (2010) 53:927-33. doi: 10.1016/j.jhep.2010.05.023

100. Miele L, Beale G, Patman G, Nobili V, Leathart J, Grieco A, et al. The Kruppel-like Factor 6 Genotype is Associated With Fibrosis in Nonalcoholic Fatty Liver Disease. Gastroenterology (2008) 135:282-91.e1. doi: 10.1053/ j.gastro.2008.04.004

101. Luukkonen PK, Zhou Y, Hyötyläinen T, Leivonen M, Arola J, OrhoMelander M, et al. The MBOAT7 Variant rs641738 Alters Hepatic Phosphatidylinositols and Increases Severity of non-Alcoholic Fatty Liver Disease in Humans. J Hepatol (2016) 65:1263-5. doi: 10.1016/ j.jhep.2016.07.045

102. Krawczyk M, Rau M, Schattenberg JM, Bantel H, Pathil A, Demir M, et al. Combined Effects of the PNPLA3 Rs738409, TM6SF2 rs58542926, and MBOAT7 rs641738 Variants on NAFLD Severity: A Multicenter BiopsyBased Study. J Lipid Res (2017) 58:247-55. doi: 10.1194/jlr.P067454

103. Dongiovanni P, Petta S, Maglio C, Fracanzani AL, Pipitone R, Mozzi E, et al. Transmembrane 6 Superfamily Member 2 Gene Variant Disentangles Nonalcoholic Steatohepatitis From Cardiovascular Disease. Hepatol Baltim Md (2015) 61:506-14. doi: 10.1002/hep.27490

104. Holmen OL, Zhang H, Fan Y, Hovelson DH, Schmidt EM, Zhou W, et al. Systematic Evaluation of Coding Variation Identifies a Candidate Causal Variant in TM6SF2 Influencing Total Cholesterol and Myocardial Infarction Risk. Nat Genet (2014) 46:345-51. doi: 10.1038/ng.2926

105. Morris AP, Voight BF, Teslovich TM, Ferreira T, Segrè AV, Steinthorsdottir V, et al. Large-Scale Association Analysis Provides Insights Into the Genetic
Architecture and Pathophysiology of Type 2 Diabetes. Nat Genet (2012) 44:981-90. doi: 10.1038/ng.2383

106. Musso G, Cipolla U, Cassader M, Pinach S, Saba F, De Michieli F, et al. Tm6sf2 rs58542926 Variant Affects Postprandial Lipoprotein Metabolism and Glucose Homeostasis in NAFLD. J Lipid Res (2017) 58:1221-9. doi: 10.1194/jlr.M075028

107. Mancina RM, Dongiovanni P, Petta S, Pingitore P, Meroni M, Rametta R, et al. The MBOAT7-TMC4 Variant Rs641738 Increases Risk of Nonalcoholic Fatty Liver Disease in Individuals of European Descent. Gastroenterology (2016) 150:1219-30.e6. doi: 10.1053/j.gastro.2016.01.032

108. Barbara M, Scott A, Alkhouri N. New Insights Into Genetic Predisposition and Novel Therapeutic Targets for Nonalcoholic Fatty Liver Disease. Hepatobiliary Surg Nutr (2018) 7:372-81. doi: 10.21037/hbsn.2018.08.05

109. Lin Y-C, Chang P-F, Chang M-H, Ni Y-H. Genetic Variants in GCKR and PNPLA3 Confer Susceptibility to Nonalcoholic Fatty Liver Disease in Obese Individuals. Am J Clin Nutr (2014) 99:869-74. doi: 10.3945/ajcn.113.079749

110. Beer NL, Tribble ND, McCulloch LJ, Roos C, Johnson PRV, Orho-Melander M, et al. The P446L Variant in GCKR Associated With Fasting Plasma Glucose and Triglyceride Levels Exerts its Effect Through Increased Glucokinase Activity in Liver. Hum Mol Genet (2009) 18:4081-8. doi: 10.1093/hmg/ddp357

111. Speliotes EK, Yerges-Armstrong LM, Wu J, Hernaez R, Kim LJ, Palmer CD, et al. Genome-Wide Association Analysis Identifies Variants Associated With Nonalcoholic Fatty Liver Disease That Have Distinct Effects on Metabolic Traits. PLoS Genet (2011) 7:e1001324. doi: 10.1371/ journal.pgen.1001324

112. Romeo S, Kozlitina J, Xing C, Pertsemlidis A, Cox D, Pennacchio LA, et al. Genetic Variation in PNPLA3 Confers Susceptibility to Nonalcoholic Fatty Liver Disease. Nat Genet (2008) 40:1461-5. doi: 10.1038/ng.257

113. Valenti L, Al-Serri A, Daly AK, Galmozzi E, Rametta R, Dongiovanni P, et al. Homozygosity for the Patatin-Like Phospholipase-3/Adiponutrin I148M Polymorphism Influences Liver Fibrosis in Patients With Nonalcoholic Fatty Liver Disease. Hepatol Baltim Md (2010) 51:1209-17. doi: 10.1002/ hep. 23622

114. Feitosa MF, Wojczynski MK, North KE, Zhang Q, Province MA, Carr JJ, et al. The ERLIN1-CHUK-CWF19L1 Gene Cluster Influences Liver Fat Deposition and Hepatic Inflammation in the NHLBI Family Heart Study. Atherosclerosis (2013) 228:175-80. doi: 10.1016/j.atherosclerosis.2013.01.038

115. Kawaguchi T, Sumida Y, Umemura A, Matsuo K, Takahashi M, Takamura T, et al. Genetic Polymorphisms of the Human PNPLA3 Gene are Strongly Associated With Severity of non-Alcoholic Fatty Liver Disease in Japanese. PLoS One (2012) 7:e38322. doi: 10.1371/journal.pone.0038322

116. Donnelly KL, Smith CI, Schwarzenberg SJ, Jessurun J, Boldt MD, Parks EJ. Sources of Fatty Acids Stored in Liver and Secreted Via Lipoproteins in Patients With Nonalcoholic Fatty Liver Disease. J Clin Invest (2005) 115:1343-51. doi: 10.1172/JCI23621

117. Wang Y, Kory N, BasuRay S, Cohen JC, Hobbs HH. Pnpla3, CGI-58, and Inhibition of Hepatic Triglyceride Hydrolysis in Mice. Hepatol Baltim Md (2019) 69:2427-41. doi: 10.1002/hep.30583

118. Pingitore P, Pirazzi C, Mancina RM, Motta BM, Indiveri C, Pujia A, et al. Recombinant PNPLA3 Protein Shows Triglyceride Hydrolase Activity and its I148M Mutation Results in Loss of Function. Biochim Biophys Acta (2014) 1841:574-80. doi: 10.1016/j.bbalip.2013.12.006

119. BasuRay S, Smagris E, Cohen JC, Hobbs HH. The PNPLA3 Variant Associated With Fatty Liver Disease (I148M) Accumulates on Lipid Droplets by Evading Ubiquitylation. Hepatol Baltim Md (2017) 66:111124. doi: $10.1002 /$ hep. 29273

120. Dongiovanni P, Donati B, Fares R, Lombardi R, Mancina RM, Romeo S, et al. Pnpla3 I148M Polymorphism and Progressive Liver Disease. World J Gastroenterol WJG (2013) 19:6969-78. doi: 10.3748/wjg.v19.i41.6969

121. Speliotes EK, Butler JL, Palmer CD, Voight BF, GIANT Consortium, MIGen Consortium, et al. PNPLA3 variants specifically confer increased risk for histologic nonalcoholic fatty liver disease but not metabolic disease. Hepatology (2010) 52:904-12

122. Sookoian S, Castaño GO, Burgueño AL, Gianotti TF, Rosselli MS, Pirola CJ. A Nonsynonymous Gene Variant in the Adiponutrin Gene is Associated With Nonalcoholic Fatty Liver Disease Severity. J Lipid Res (2009) 50:21116. doi: 10.1194/jlr.P900013-JLR200 
123. Rotman Y, Koh C, Zmuda JM, Kleiner DE, Liang TJ. he association of genetic variability in patatin-like phospholipase domain-containing protein 3 (PNPLA3) with histological severity of nonalcoholic fatty liver disease. Hepatology (2010) 52:894-903. doi: 10.1073/pnas.1901974116

124. BasuRay S, Wang Y, Smagris E, Cohen JC, Hobbs HH. Accumulation of PNPLA3 on Lipid Droplets is the Basis of Associated Hepatic Steatosis. Proc Natl Acad Sci USA (2019) 116:9521-6. doi: 10.1073/pnas.1901974116

125. Bruschi FV, Claudel T, Tardelli M, Caligiuri A, Stulnig TM, Marra F, et al. The PNPLA3 I148M Variant Modulates the Fibrogenic Phenotype of Human Hepatic Stellate Cells. Hepatol Baltim Md (2017) 65:1875-90. doi: 10.1002/hep.29041

126. Bruschi FV, Tardelli M, Einwallner E, Claudel T, Trauner M. Pnpla3 I148M Up-Regulates Hedgehog and Yap Signaling in Human Hepatic Stellate Cells. Int J Mol Sci (2020) 21. doi: 10.3390/ijms21228711

127. Donati B, Motta BM, Pingitore P, Meroni M, Pietrelli A, Alisi A, et al. The Rs2294918 E434K Variant Modulates Patatin-Like Phospholipase DomainContaining 3 Expression and Liver Damage. Hepatology (2016) 63:787-98. doi: 10.1002/hep. 28370

128. Chen W, Chang B, Li L, Chan L. Patatin-Like Phospholipase DomainContaining 3/Adiponutrin Deficiency in Mice is Not Associated With Fatty Liver Disease. Hepatol Baltim Md (2010) 52:1134-42. doi: 10.1002/hep.23812

129. He S, McPhaul C, Li JZ, Garuti R, Kinch L, Grishin NV, et al. A Sequence Variation (I148M) in PNPLA3 Associated With Nonalcoholic Fatty Liver Disease Disrupts Triglyceride Hydrolysis. J Biol Chem (2010) 285:6706-15. doi: 10.1074/jbc.M109.064501

130. Smagris E, BasuRay S, Li J, Huang Y, Lai KV, Gromada J, et al. Pnpla3I148M Knockin Mice Accumulate PNPLA3 on Lipid Droplets and Develop Hepatic Steatosis. Hepatol Baltim Md (2015) 61:108-18. doi: 10.1002/hep.27242
131. Banini BA, Kumar DP, Cazanave S, Seneshaw M, Mirshahi F, Santhekadur $\mathrm{PK}$, et al. Identification of a Metabolic, Transcriptomic and Molecular Signature of PNPLA3-mediated Acceleration of Steatohepatitis. Hepatology (2021) 73:1290-306. doi: 10.1002/hep.31609

132. Valenti L, Dongiovanni P. Mutant PNPLA3 I148M Protein as Pharmacological Target for Liver Disease. Hepatology (2017) 66:1026-8. doi: 10.1002/hep.29298

Conflict of Interest: AJS is President of Sanyal Biotechnology and has stock options in Genfit, Akarna, Tiziana, Indalo, Durect, Exhalenz and Hemoshear. He has served as a consultant to Astra Zeneca, Conatus, Coherus, Bristol Myers Squibb, Blade, Tobira, Takeda, Siemens, Merck, Genentech, Tern, Gilead, Lilly, Poxel, Artham, Boehringer Ingelhiem, Novo Nordisk, NGM Bio, Birdrock, Novartis, Pfizer, and Genfit. He has been an unpaid consultant to Intercept, Echosens, Perspectum, Immuron, Galectin, Fractyl, Affimune, Chemomab, Nordic Bioscience. His institution has received grant support from Gilead, Salix, Tobira, Intercept, Bristol Myers, Shire, Merck, Astra Zeneca, Malinckrodt, Cumberland and Novartis. He receives royalties from Elsevier and UptoDate.

The remaining author declares that the research was conducted in the absence of any commercial or financial relationships that could be construed as a potential conflict of interest.

Copyright (c) 2021 Albhaisi and Sanyal. This is an open-access article distributed under the terms of the Creative Commons Attribution License (CC BY). The use, distribution or reproduction in other forums is permitted, provided the original author(s) and the copyright owner(s) are credited and that the original publication in this journal is cited, in accordance with accepted academic practice. No use, distribution or reproduction is permitted which does not comply with these terms. 